\title{
A Study of Truck Parking Facilities' Adequacy in Brazilian Federal Highways
}

\author{
Amir Mattar Valente, Caroline Mazzuco Furlan, Eduardo Lobo and Jorge Destri Junior \\ Transportation and Logistics Laboratory (LabTrans), Federal University of Santa Catarina (UFSC), Florianópolis 88040-970, \\ Brazil
}

\begin{abstract}
According to Brazilian reports of large trucks accidents on Federal Highway, fatigue and speeding are the major contributors to those accidents in which drivers are trying to meet short delivery deadlines for long hauls. A new federal law has been approved to limit truck drivers' working times, including maximum continuous driving time and maximum daily and weekly on-duty time. We present a study that aims at analyzing whether the existing resting areas on federal highways have sufficient capacity to meet current and future demand for truck stops. We have established the following method: In the first step, we review and study different models found in the literature and evaluate their potential application to Brazilian conditions; In the next step, we develop our own model and, finally, validate it using data from BR-101 Federal Highway, in Santa Catarina State. Tests made using part of collected data (which were subjected to statistical treatment) showed satisfactory results, indicating that the demand behavior was consistent with that observed in the field and the answers provided by truck drivers in the interviews. The research has yet to complete processing all data and it also must be repeated in other regions with different characteristics.
\end{abstract}

Key words: Hours of service, truck parking, rest areas, truck stop.

\section{Introduction}

Considering that many highway accidents in Brazil involve professional truck drivers, regulating the professional's maximum driving time and working hours became essential [1]. Act-12619/2012 [2], enacted by the Brazilian government, regulates working hours of freight and passenger vehicles drivers, aiming at decreasing the amount of accidents caused by fatigue from excessive driving time.

A partnership between the DNIT (National Department of Transport Infrastructure), Ministry of Transports and the LabTrans/UFSC (Transports and Logistics Laboratory of the Federal University of Santa Catarina) aims at creating a calculation methodology that allows for the evaluation of the adequacy of Brazilian highways to meet the requirements of the new law. To establish the new method, a three-step process was adopted: analysis, implementation and

\footnotetext{
Corresponding author: Jorge Destri Junior, Dr., research fields: transportation and logistics. E-mail: Jorge.destri@labtrans.ufsc.br.
}

validation, which are described, respectively, in Sections 2, 3 and 4. In the first stage, the existing literature models are revised using as reference the United States [3], Canada [4] and the European Union [5]. In the implementation stage, a model appropriate to Brazilian reality is elaborated, and, in the validation stage, the new method is applied to a stretch of a Brazilian Federal Highway as a pilot project. When the method is properly developed, there will be a computational tool available to allow it to be employed by associated government agencies. In this study, the results of the first two stages and part of the evaluation method are presented.

\section{Theoretical Basis}

Act-12619/2012 provides for the practice of drivers' profession, regulating and ruling on work hours and driving time for professional drivers. According to this law, a professional driver is prohibited to drive continuously for a period longer than four hours; After that time, the driver must rest for $30 \mathrm{~min}$. However, 
there is a grace period of up to one hour to allow the driver to find an adequate and secure resting site. In addition to that, the driver must rest for $11 \mathrm{~h}$ within a 24-h period, which may be divided in two periods, a 9-h one and a 2-h one, provided they occur in the same day.

The law creates a typical case of relationship between supply and demand, that is, on the one hand we have the need for drivers to observe rest periods (short or longer) and, on the other hand, we have a limited amount of parking spaces over time. While the supply is easily calculated, demand involves many probabilistic factors, which are difficult to determine. In this context, among the analyzed references, three models to determine the demand stood out.

The model created by Lüttmerding [6] calculates the truck parking demand along a stretch of highway for each of its driving directions; The demand for TPS (truck parking spaces) by kilometer is based on parameters of average DTV (daily traffic volume) of trucks over $3.5 \mathrm{t}$ in a given direction, average daily driving distance covered by trucks (HGV (heavy goods vehicles)) per day ( $\phi D D)$ that are driven along the segment, average parking duration (regular $11 \mathrm{~h}$, shortened $9 \mathrm{~h})(\phi P D)$, night-time or the period commonly used by the drivers to rest $\left(t_{N}\right)$, the proportion of cumulative stop time during night-time $\left(P_{N}\right)$ and the proportion of long-distance traffic $\left(P_{L D}\right)$. The resulting values are usually applicable only to the surveyed stretch or region where they were obtained. The demand is expressed in number of parking spaces per kilometer and determined by the following formula:

$$
\frac{T P S}{k m}=\left(\frac{D T V}{\phi D D}\right) \times\left(\frac{\phi P D}{24}\right) \times\left(\frac{24}{t_{N}}\right) \times P_{N} \times P_{L D}
$$

The second model has been originally developed by the MnDOT (Minnesota Department of Transports/USA) [7] and presented by Garber and Wang [8]. The model is used in estimating required truck parking spaces. The demand in this model is calculated as follows:

$$
N T S P A C E S=\frac{A D T \times P \times D H \times D_{t} \times P F}{V H S}
$$

where:

NTSPACES $=$ number of truck parking spaces required;

$A D T=$ average daily traffic with access to rest area;

$P=$ total percentage of mainline traffic stopping at rest area;

$D H=$ design hour usage, design hour compares the design hourly volume, usually the 30th to 50th highest hourly volume, to the annual $A D T$, producing a factor that predicts a peak usage average-hour situation;

$D_{t}=$ percentage of truck parking spaces;

$P F=$ peak factor; this is the ratio of average day of five summer months to average day of year;

$V H S=$ number of vehicles parked per hour per space.

As time goes by, other institutions, like the VDOT (Virginia Department of Transportation) [8] and Apogee Research [9], have developed surveys to verify or even adequate these parameters to new scenarios/case studies, such as the model proposed by Lüttmerding [6]. However, this model does not take into account legal issues related to the regulation of HOS (hours of service) [3].

The third model is based on the fact that, in the USA, there are two kinds of places where freight vehicles may stop: (1) rest and park areas: places operated by state public service with minimum services (water, toilets and vending machines), which usually place restrictions on maximum stop time; (2) park areas: private places which provide an improved infrastructure to meet drivers' requirements in short- or long-duration stops [10]. In its full version, the model adopted by the FHWA (Federal Highway Administration) [11] has different provisions for vehicles that cover long distances (need more stops) and for those that cover short distances, as well as for the kind of preferred stopping places. Considering only the vehicles that cover long distances and that do not have a preferred stopping place, the average THT (truck-hours of travel per day) is estimated using the 
following parameters: the percentage of commercial trucks in the total number of vehicles $\left(P_{t}\right)$; the $A A D T$ (annual average daily traffic); the length of the roadway segment $(L)$ and the average speed of the trucks $(S)[12]$ :

$$
T H T=P_{t} \times A A D T \times \frac{L}{S}
$$

Next, the following parameters are estimated: the average stop time for each driving hour for long-haul drivers $\left(T_{\text {DRIVING }}\right)$; the time at home for long-haul drivers $\left(T_{H O M E}\right)$; the loading and unloading for long-haul drivers $\left(T_{L O A D / U N L O A D}\right)$; the time at shipper/receiver for long-haul drivers $\left(T_{\text {SHIPPER/RECEIVER }}\right)$ - this last term refers to the average stop time per hour throughout daytime with a purpose other than resting. With these parameters, the estimate average parking time per truck-hour of travel is calculated $\left(P_{\text {avg }}\right)$ :

$$
P_{\text {avg }}=\frac{\left(8 \mathrm{~d} \times \frac{24 \mathrm{~h}}{\mathrm{~d}}\right)-T_{\text {DRIVNG }}-T_{\text {HOME }}-T_{\text {LOAD/UNLOAD }}-T_{\text {SHIPPER/RECEIVER }}}{T_{\text {DRIING }}}+\frac{5 \mathrm{~min}}{60 \mathrm{~min}}
$$

The simplified demand model $(D)$ is based on the total $T H T$ and the average parking time per truck-hour of travel $\left(P_{\text {avg }}\right)$ :

$$
D=T H T \times P_{a v g}
$$

From the three presented models, the one adopted by FHWA [11] is considered the most similar to the one proposed in this study, since its parameters take short and long stopping times into account.

\section{Proposed Methodology}

The methodology elaborated in this study follows a basic assumption, determined by the agencies involved in the project, i.e., the division of the Brazilian Highway Network into segments delimitated by PRF (Federal Highway Police) stations, as illustrated in Fig. 1. The analysis of parking spaces supply and demand is made for each segment individually; the calculations are carried out by traffic direction and then consolidated where there are no lane crossing restrictions. Both short and long stopping times which are provided for in law are taken into account.

Initially, the demand for vacancies (how many drivers need to stop, and for how long, in a given highway segment) is calculated; Then, the vacancy availability in the same segment is evaluated. Once these two values are determined, the excess or shortage of parking spaces for that segment is assessed, so it may provide support to the pertinent decision-making for each case.

The methodology consists in the following steps:

(1) obtaining legal parameters related to the restriction to work hours, in other words, minimum rest period, maximum time between rest periods, maximum time of continuous driving, minimum stopping time between driving hours;

(2) determining coefficients that will be used as safety margin for the calculations;

(3) determining the highway segments to be assessed;

(4) obtaining, for each segment, its operation parameters, i.e., $A D T$ (daily average traffic volume), percentage of $A D T$ per traffic direction, $A D T$ frequency distribution throughout the day, travel time probability distribution for each hour of the day (due to high cost and difficulty of obtaining this parameter, one hour may be used for the whole day, considering peak hours, or one for each representative period, like morning, afternoon and evening), percentage of drivers who need to stop for rest at each hour of the day;

(5) identifying, for each segment, the facilities that may be used by freight vehicle drivers to stop and rest in each direction of the highway, registering the number of available parking spaces in each one;

(6) calculating the expected traffic volume per hour for each segment and traffic direction, based on $A D T$, the breakdown of traffic by direction and $A D T$ frequency throughout the day; 


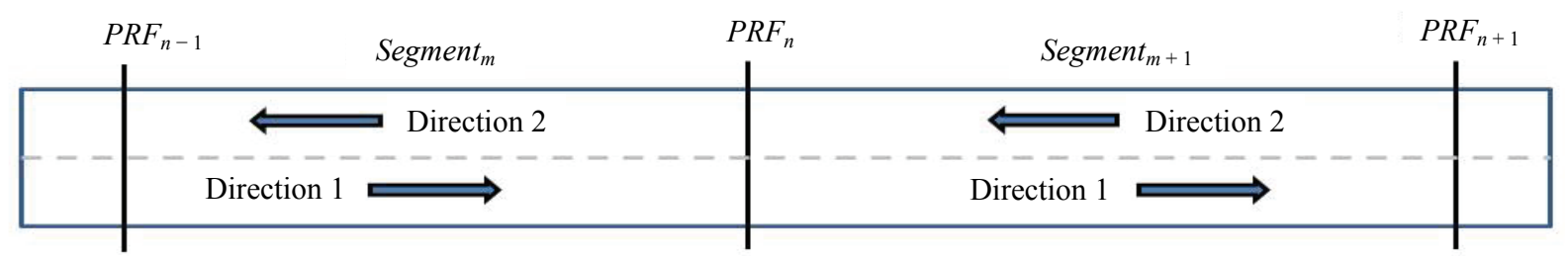

Fig. 1 Representation of the limits of the segments and the respective directions.

Source: LabTrans.

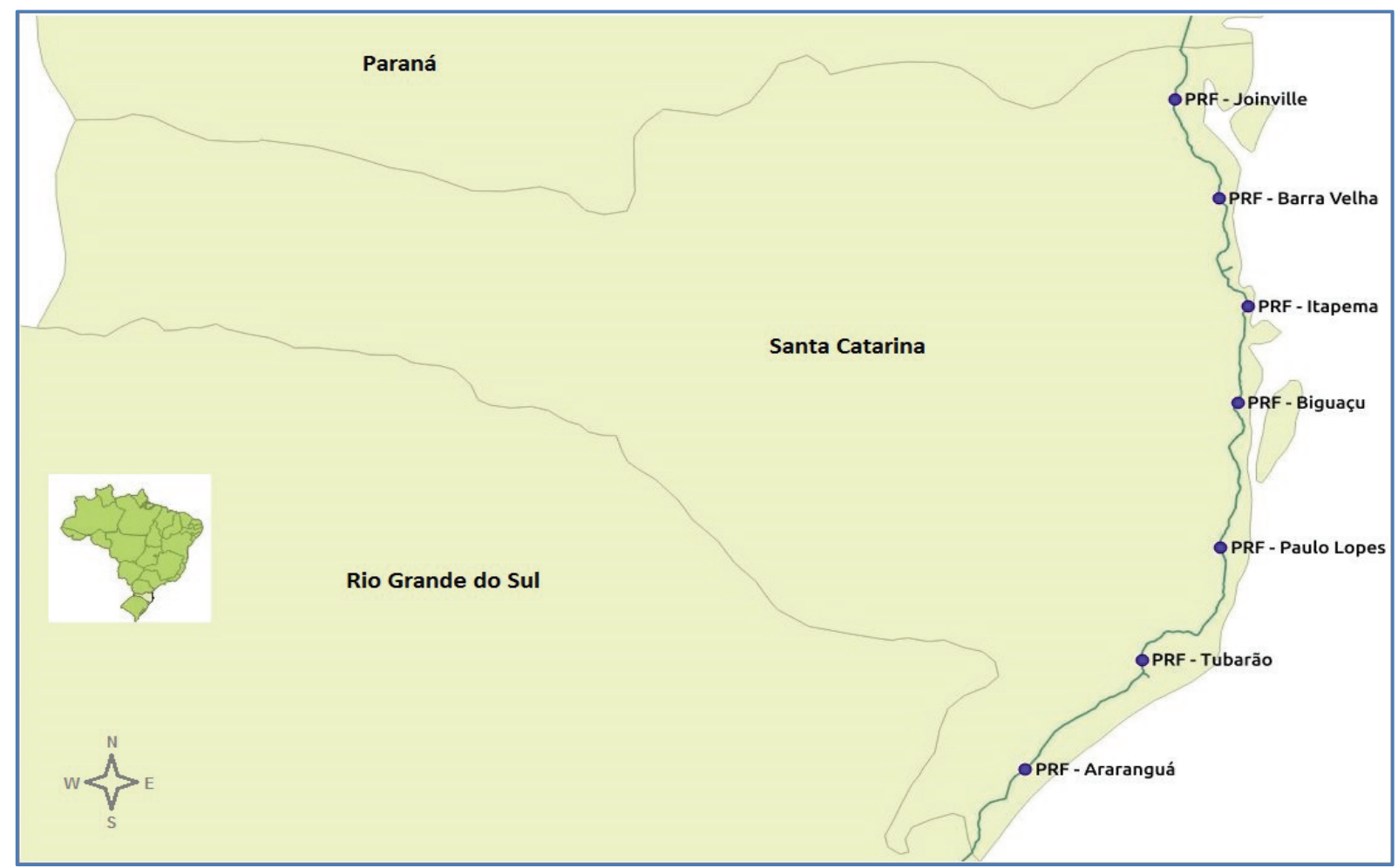

Fig. 2 Federal Highway BR-101, Santa Catarina, and Federal Police Stations.

Source: LabTrans.

(7) calculating the expected number of short-length stops per hour for each segment and traffic direction, based on expected traffic volume, travel time probability distribution, legal parameters and safety values;

(8) calculating the expected long-length stops (rest) per hour for each segment and traffic direction, based on expected traffic volume, expected percentage time for rest, legal parameters and safety values;

(9) calculating the availability of parking spaces by adding up existing parking places;

(10) verifying the excess or shortage of parking spaces in each segment, compared to the expected number of short-length stopping time plus the expected number of long-length stopping time with the calculated offer, grouped by traffic direction, if reasonable.

\section{Methodology's Evaluation}

To validate the elaborated methodology, a pilot project was executed along a stretch of highway BR-101, which crosses the State of Santa Catarina, located in South Brazil. This stretch is $465 \mathrm{~km}$ long and has seven PRF stations, as shown in Fig. 2.

Operational data were obtained from four different sources:

- government agencies;

- highway toll operators; 
- quantitative research for gathering data related to driving, stop and rest times in PRF stations. A number of 3,343 freight vehicle drivers were interviewed with an average of 238 interviews per station, per traffic direction. In two segments, the parked vehicles were also counted;

- traffic volume classification counts.

Data on facilities with parking spaces were obtained from a survey made by the Ministry of Transports. Fig. 3 shows the distribution curve of the average travel time (since the last stop) for a sample of 212 trucks along the segment between Joinville and Barra Velha PRF stations, in the south-north direction.

For the same segment and traffic direction, Fig. 4 shows, in percentages, how the volume of heavy vehicles is distributed along a $24-\mathrm{h}$ period, considering a typical day.

At present, data related to traffic volume for a segment are still being collected, while some data originated from the quantitative research are receiving statistical treatment using a mixed linear model [13] with the aid of Software R [14]. Longitudinal planning is frequently used in several research areas, since they allow for assessment of global or individual changes along a time scale [15], so as to eliminate outlier values.

Despite this situation, a prototype computer program was created to receive data and perform the calculations predicted in the methodology. Available data are already stored in the program and missing data were extrapolated from existing data in non-official sources. Using these data (from surveyed and estimated ones), tests with the software were performed to verify the consistency and integrity of proposed calculations. From these tests, two important facts were observed. The first is that the estimated demand for any one hour, due to rest time (long haul), affected the estimated demand of subsequent hours. The second fact was that there was no need for using a probability distribution for travel time from the last rest period. This was replaced by a percentage of expected vehicles stopped for each hour of the day. Adjustments were made in the mathematical model and program. Further tests were performed and results were consistent, even when using some dummy data.

An example of the methodology's use, on a single traffic direction between Itapema and Biguaçu PRF stations, is shown in Fig. 5. In this chart, the expected

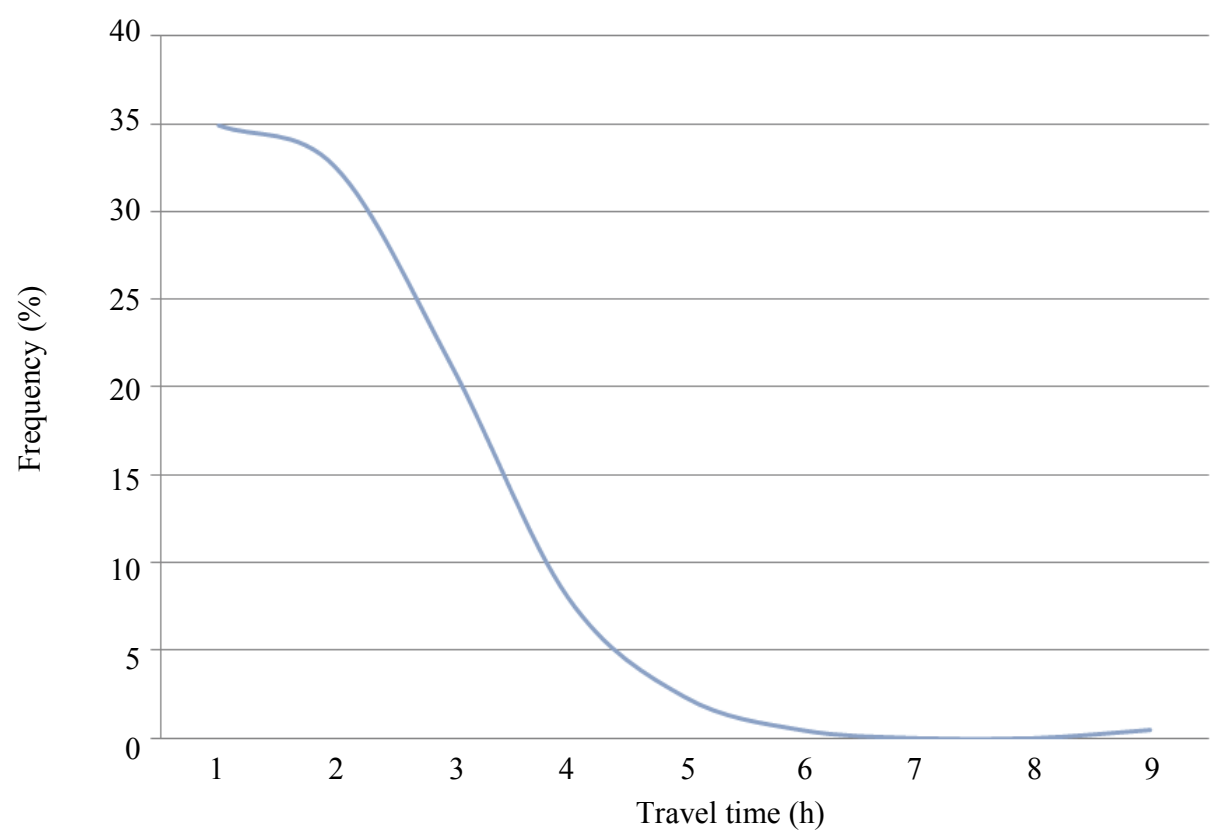

Fig. 3 Frequency distribution curve by travel time.

Source: LabTrans. 


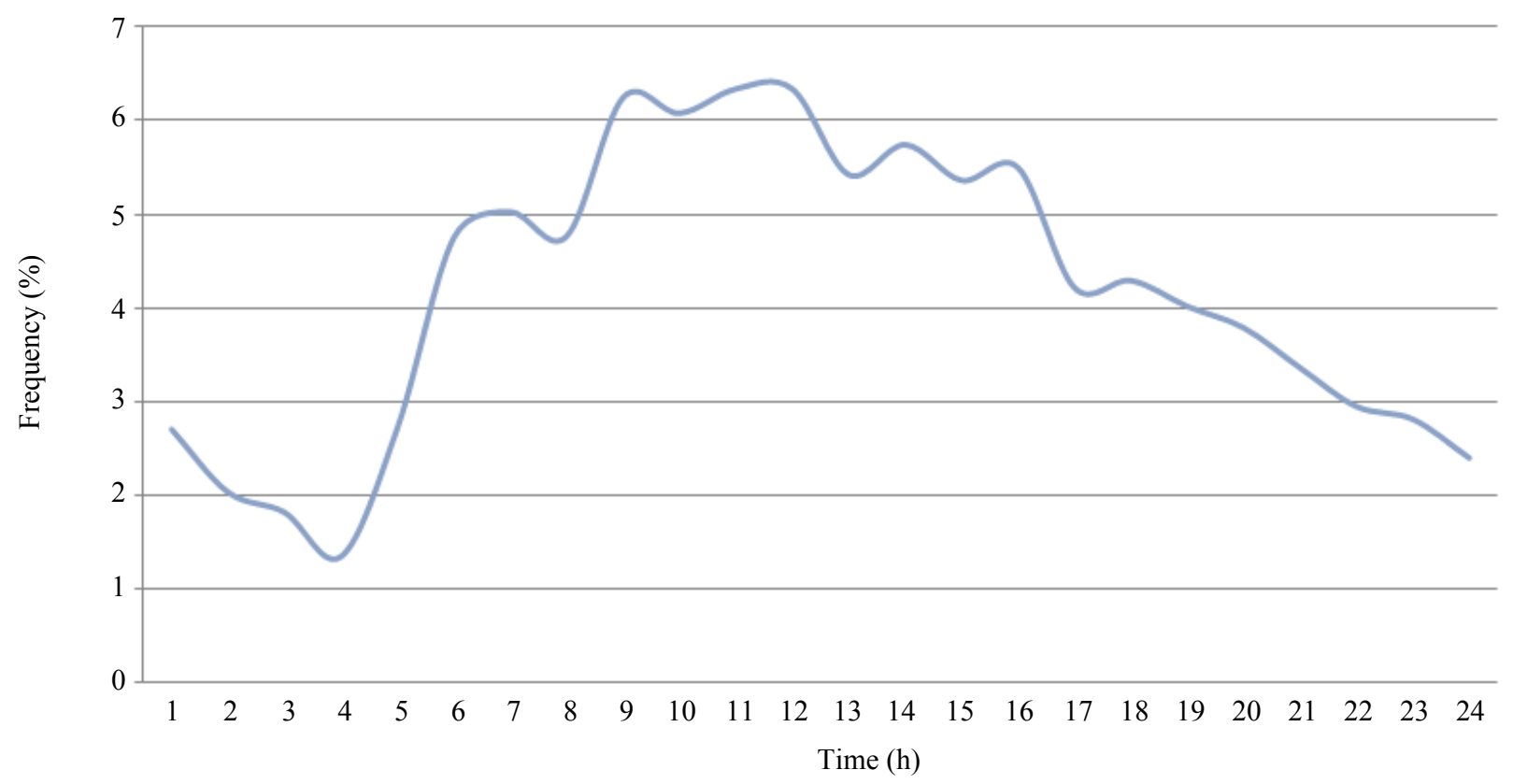

Fig. 4 Volume frequency distribution curve.

Source: Autopista Litoral Sul/LabTrans.

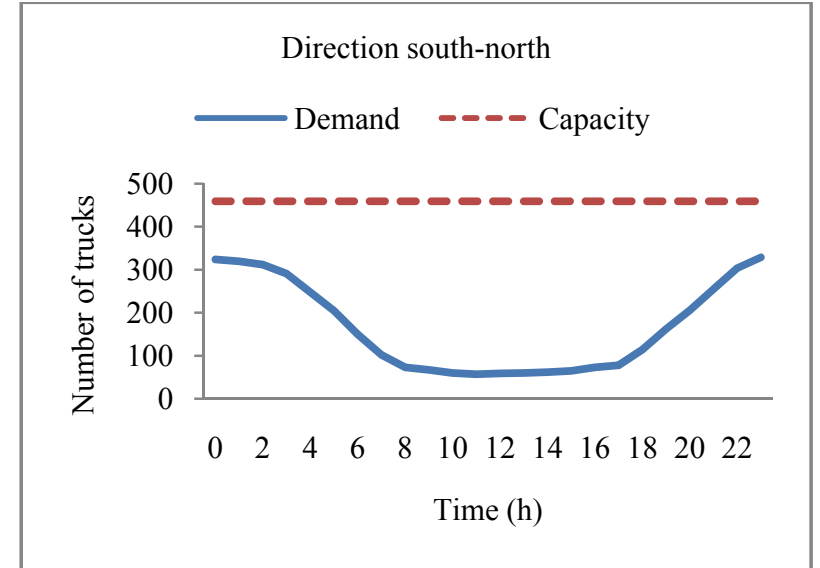

Fig. 5 Capacity and demand per hour in segment between Itapema and Biguaçu PRF stations.

Source: LabTrans.

demand is $30 \%$ lower than the capacity in peak hours, which is consistent with the parking spaces' surplus showed in the drivers' surveys and parking areas' checks. Results of tests performed on other pilot segments were also consistent with the surveys, indicating that the developed methodology seems adequate to its purpose.

\section{Conclusions}

This article presented a methodology to determine parking spaces' capacity and expected demand, in conformity with Brazilian regulation. Methods used in the United States, Canada and European Union were evaluated and a new methodology, adapted to Brazilian conditions, was proposed. This new methodology was then evaluated on part of a $465-\mathrm{km}$ segment of BR-101 Highway and showed adequate results. Tests using all data from the pilot project still need to be performed to verify the sensitivity of the method when using actual data for all segments.

In its current form, this method allows DNIT the evaluation of a road segment conformity to Act-12619/2012. However, it relies on the calculation of probability distributions for the travel and rest times, which is a laborious and time-consuming task. The adopted research method should be improved, and automated tools should be used before it is used on a nationwide scale. In a future stage, the method should be applied in other places with different characteristics from those found in the pilot project: few available parking sites and long segments-a typical situation in the north, northeast and mid-west regions of Brazil. 


\section{Acknowledgments}

The authors would like to thank the DNIT (National Department of Transport Infrastructure) for sponsoring this research.

\section{References}

[1] Laboratório de Transportes e Logística, UFSC (Universidade Federal de Santa Catarina). 2013. Studies, Research and Training Programs for Development and Consolidation of Methods and Processes to Support Management CGPERT's Activities Related to Road Safety Areas and Road Operations. Object 2-Road Safety 2R05, Partial Report, DNIT (Departamento Nacional de Infraestrutura de Transportes) Internal report.

[2] Brazil Law. 2012. "Brazil Law No. 12.619/2012, 04/30/2012. Professional Drivers' Regulation and Changes the Consolidation of Labor Laws." Brazil Law. Accessed October 22, 2013. http://www.planalto.gov.br/ ccivil_03/_ato2011-2014/2012/lei/112619.htm.

[3] FMCSA (Federal Motor Carrier Safety Administration). 2011. "Hours of Service of Drivers". U.S. Department of Transportation. Accessed December 2, 2013. http://www.gpo.gov/fdsys/pkg/FR-2011-12-27/pdf/201132696.pdf.

[4] CCMTA (Canadian Council of Motor Transport Administrators). 2007. "Commercial Vehicle Drivers Hours of Service Regulations of October 25, 2005-Application Guide." CCMTA. Accessed December 2, 2013. http://laws-lois.justice.gc.ca/eng/ regulations/SOR-2005-313/page-1.html.

[5] European Union. "Regulation (Ec) No. 561/2006 of the European Parliament and of the Council of March 15, 2006." European Union. Accessed January 10, 2015. http://eur-lex.europa.eu/resource.html?uri=cellar:5cf5ebd e-d494-40eb-86a7-2131294ccbd9.0005.02/DOC_1\&form at $=$ PDF.

[6] Lüttmerding, A. 2009. "Calculation Model for Estimating the Demand of Truck Parking Areas along Motorways." Presented at the 12th International Conference on Transport Science, Portorož, Slovenija.

[7] FHWA. 1996. Department of Transportation, U.S. Commercial Driver Rest and Parking Requirements: Making Space for Safety. FHWA-MC-96-0010. Washington, D.C.: Federal HighwayAdministration.

[8] Garber, N. J., and Wang, H. 2004. Estimation Is the Demand for Commercial Truck Parking on Interstate Highways in Virginia. Final report, Virginia Transportation Research Council.

[9] Trucking Research Institute, Apogee Research, Inc., and Wilbur Smith and Associates. 1996. Commercial Drivers Rest Area Requirements: No Room at the Inn. Washington, D.C.: Federal Highway Administration.

[10] Georgia Department of Transportation. 2011. Statewide Freight and Logistics Plan-Truck Modal Profile. Atlanta: Georgia Department of Transportation.

[11] FHWA. Study of Adequacy of Commercial Truck Parking Facilities. Technical Report FHWA RD-01-158, Federal Highway Administration, U.S. Department of Transportation.

[12] Coleman, J. A., and Trentacoste, M. F. 2002. Model Development for National Assessment of Commercial Vehicle Parking. FHWA-RD-01-159. Washington, D.C.: FHWA (Federal Highway Administration), U.S. Department of Transportation.

[13] Pinheiro, J. C., and Bates, D. 2000. Mixed Effects Model in $S$ and $S=P L U S$. New York: Springer-Verlag, 528.

[14] Bates, D. M. 2010. "Mixed-Effects Modeling with R." Springer. Accessed February 2, 2014. http://lme4.r-forge.r-project.org/book/.

[15] Singer, J., Nobre, J. S., and Rocha, F. M. M. 2009. Longitudinal Data Analysis (Análise de Dados Longitudinais). Prague: Apostila, 158. 